\section{КУЛЬТУРА ИННОВАЦИОННОЙ ДЕЯТЕЛЬНОСТИ В ОРГАНИЗАЦИЯХ: СОВРЕМЕННЫЕ ПРАКТИКИ И МЕТОДЫ РАЗВИТИЯ}

Аннотация:

Статья посвящена анализу путей повышения уровня культуры инновационной деятельности организаций в современных условиях. На примере инновационных практик известных компаний рассмотрены условия, позволяющие эффективно внедрять инновации, создавать культуру инновационной активности на предприятии, где кадры получают возможность участия в генерировании разных идей и подготовке революционных решений. Особое внимание в работе этих компаний уделяется сотрудникам, которые должны динамично развивать мышление и реализовывать на практике инновационные проекты - внедрять новиества. Применение гибких методов и инструментов позволяет стимулировать новые практики, создавать возможности для общения между представителями разных отделов и подразделений. Совместная межфункциональная работа способствует сплочению коллектива, повышению производительности и популяризации бренда. Важное значение в формировании и развитии культуры инновационной деятельности имеет наличие времени для работы над идеями. Компании должны быть открыты для всех новых проектов, поочрять творчество и изобретательность сотрудников, задавая правильный тон и стимулируя инновации.

Ключевые слова:

культура инновационной деятельности, инновационная активность, изобретательность, креативность, инновационное мышление, инновационные разработки.
Lomonosov Moscow State University

\section{CULTURE OF INNOVATION IN ORGANIZATIONS: MODERN PRACTICES AND DEVELOPMENT METHODS}

\begin{abstract}
Summary:
The research analyzes the ways to improve a culture of innovation in organizations in the modern context. By a case study of innovative practices of well-known companies, the conditions are considered that enable them to effectively implement innovations and create the culture of innovation where the staff gets the opportunity to be involved in generating various ideas and developing revolutionary solutions. These organizations pay special attention to employees who must dynamically develop their thinking and put innovative projects into practice, i.e. introduce innovations. Flexible methods and tools allow companies to stimulate new practices and create opportunities for communication between employees from different departments and divisions. Joint cross-functional work helps build a team, increase productivity, and promote the company's brand. The availability of time to work on ideas is important in creating and developing the culture of innovation. Companies should be open to all new projects, encourage creativity and ingenuity of employees setting the tone for it and stimulating innovation.
\end{abstract}

Keywords: culture of innovation, innovation activity, ingenuity, creativity, innovative thinking, innovation.

Высокая технологичность выступает характерной приметой современности. В условиях конкурентной борьбы многие компании для поиска адекватных ответов на требования времени должны совершенствовать инновационную культуру. Поэтому сегодня социологический анализ инновационной деятельности является актуальным и востребованным в обществе. При интенсивных изменениях необходимо изучение инновационной активности с позиции междисциплинарного подхода. При этом особое значение имеет исследование социальных трансформаций, обеспечивающих дальнейшее перспективное развитие общества.

Социологическое изучение инновационной деятельности позволяет определить сущность, функции, перспективы реализации инноваций, выявить их воздействие на разные социальные процессы. Под инновационной деятельностью мы понимаем комплекс мероприятий, направленных на создание, внедрение и освоение результатов научно-исследовательских и опытно-конструкторских работ (НИОКР), обеспечивающих социальный и (или) иной эффект.

Современные методы социологического исследования, связанные с анализом возможностей, преимуществ и перспектив инновационной деятельности, становятся востребованными. 
Данное обстоятельство обусловлено повышением социальной динамики, усложнением механизмов функционирования социально-экономических систем, а также необходимостью получения объективной информации об их состоянии и грядущих трансформациях.

Новаторство, креативность и изобретательность как общественные феномены долгое время находятся в поле зрения социологической науки. Теоретико-методологической основой исследования послужили работы отечественных и зарубежных авторов Н.А. Бердяева, П.А. Сорокина, И.Н. Дубиной, Д. Белла, Э. Майклза, Х. Хэндфилд-Джонса, К. Кристенсена и многих других. В трудах ученых рассмотрены подходы к социальному управлению кадровым потенциалом в организациях, методы активизации и стимулирования творческой деятельности работников, инструменты формирования и развития благоприятной инновационной среды, а также другие важные аспекты [1].

Формирование и развитие благоприятной инновационной среды - это не просто популярные и современные фрормулировки, а именно то ключевое преимущество, которое выгодно отличает успешные организации от конкурентов. Бизнес-среда часто ориентирована на прагматичные результаты и быструю экономическую отдачу, что весьма затрудняет создание культуры инновационной деятельности, направленной на новые идеи и наукоемкие разработки в долгосрочной перспективе.

Культура инновационной деятельности представляет собой систему ценностей, норм, правил, предположений и убеждений сотрудников организации, способствующих принятию новой методологии и практики, генерации инновационных идей и революционных решений, адаптации, настройке или трансформации существующих продуктов/услуг в целях придания им нового значения/свойства, значительно увеличивающего значимость НИОКР. Под развитием культуры инновационной деятельности мы понимаем перманентное совершенствование условий, повышающих уровень инновационной активности сотрудников организации, формирующих собственную позицию и манеру поведения, в которых воплощаются ключевые ценности (нацеленность на развитие и благополучие фирмы, коллективизм, карьерный рост и т. д.).

Потребность в инновациях со стороны многих компаний обусловлена необходимостью решения проблем социального, экономического, технологического, экологического и иного характера. В то же время наиболее успешные организации предпочитают разрабатывать и внедрять инновации, чтобы занять выгодные позиции в сфере наукоемких разработок. Такие технологические гиганты, как Google и Apple, смогли высоко поднять планку в инновационной активности, изменив представление о привычных и, казалось бы, незыблемых традициях и рутинных процессах.

ByrneWallace является одной из крупнейших юридических фирм в Ирландии, защищающей и продвигающей интересы клиентов путем предоставления экспертных юридических услуг. Компания активно применяет современные инновационные технологии, позволяющие повышать качество взаимодействия с заказчиками, развивать умение понимать потребности предпринимателей и осуществлять более эфффективное обслуживание. Как свидетельствует М. Уолш, представитель и партнер ByrneWallace: «Мы активно используем программное обеспечение, которое помогает нам уникальным образом управлять сложными и объемными процессами. Одним из преимуществ обращения к современным технологиям является способность безопасно экспортировать данные проекта клиентам. Это увеличивает информационные потоки, а также укрепляет сотрудничество с контрагентами» [2].

Современные технологии в связке с творчеством и креативностью персонала способствуют расширению взаимодействия, позволяют усилить связи с клиентами и использовать коллективный опыт команды ByrneWallace. Сотрудники фирмы активно участвуют в развитии и поддержке культуры инновационной деятельности в компании, продвигая научные идеи и перспективные разработки. Например, была внедрена «доска объявлений» во внутренней сети, чтобы все работники могли высказать мнение в отношении каких-либо улучшений и (или) изменений.

Для того чтобы эффективно внедрять и осваивать инновации, компаниям необходимо формировать и совершенствовать культуру инновационной деятельности, в которой личному составу предлагается генерировать идеи и разрабатывать революционные решения. Сотрудники организаций должны активно развивать мышление и реализовывать на практике инновационные проекты.

Компания Intel, являющаяся известным производителем электронных устройств и компьютерных компонентов, включая микропроцессоры и наборы системной логики (чипсеты), создала инновационную технологию Open Lab, чтобы облегчить и расширить возможности открытых исследований и инноваций. М. Керли, директор Intel Labs Europe, отмечает, что в Open Lab по периметру размещены доски, чтобы сотрудники могли импровизировать и создавать прототипы в режиме реального времени. В этом помещении царит атмосфера, позволяющая работникам проявлять новаторские способности. По его мнению, руководство многих организаций не принимает во внимание необходимость фоорирования и развития культуры инновационной деятельности до того этапа, при котором генерирование идей и перспективное планирование начинают восприниматься как ключевые инструменты современного развития и повышения уровня конкурентоспособности 
[3]. Важно создать позитивное отношение к нововведениям, что позволит стимулировать персонал рисковать и генерировать перспективные идеи и разрабатывать революционные решения.

Представители руководства компаний должны дать понять персоналу, что они открыты для инноваций. Некоторые компании делают это, создавая специальное творческое пространство, где сотрудники могут проявлять новаторский подход. Однако в большинстве офисных помещений, разграниченных на множество секторов, фризически и эмоционально недостаточно места для вдохновения, креативности и изобретательности.

Интересной практикой формирования культуры инновационной деятельности является опыт британской компании Vodafone Group Plc - одного из крупнейших в мире операторов сотовой связи. Организация предлагает услуги мобильной связи в 26 странах мира. Vodafone Group Plc потратила 2,5 млн евро на реконструкцию офисных помещений в Леопардстауне (г. Дублин), ликвидацию индивидуальных кабинетов, кабинок и залов заседания, тем самым создав открытые пространства, где сотрудники могут пообщаться и выпить кофе, а символов власти или привилегий больше не существует. Работники располагаются там, где могут найти свободное место, даже у генерального директора нет личного стола. Директор по персоналу Vodafone в Ирландии, Р. Муни, отмечает, что «сотрудники разных компаний работали в индивидуальных помещениях, это сдерживало новые идеи и креативность, и мы решили создать новую рабочую среду, которая будет стимулировать общение, новаторство и креативность». По ее мнению, применение новых гибких методов и инструментов развития культуры инновационной деятельности позволяет стимулировать инновации, создавать возможности для общения между представителями не только разных отделов, но, что наиболее важно, разных уровней [4]. Совместная межфункциональная активность привела к возрастанию сплоченности команды, формированию системы норм/правил, взаимодействию работников, повышению производительности труда и популяризации бренда Vodafone Group Plc.

Особое значение в формировании и развитии культуры инновационной деятельности в организации имеет понимание менеджментом важности наличия времени у сотрудников для работы над идеями. Поэтому все большее число компаний предоставляют персоналу по желанию возможность для творчества, включенную в повседневный ресурс рабочего времени. Например, Google выделяет работникам 20 \% времени на реализацию идей и деятельность, связанную с инициативными внутрипроизводственными проектами. Наряду с предоставлением коллективу временного ресурса для проявления изобретательности и креативности многие предприятия культивируют подобную активность посредством проведения дней инноваций, фестивалей идей, сеансов хакатона, позволяющих специалистам из разных областей работать сообща над решением каких-либо задач.

Австралийская компания - разработчик программного обеспечения Atlassian призывает сотрудников использовать оплачиваемые выходные дни для решения любых задач и работы над перспективными проектами. Как правило, руководство инновационных фирм не осуществляет пристального контроля за выполнением персоналом трудовых обязанностей. Менеджмент указанной организации предоставляет людям возможность самостоятельно распоряжаться рабочим временем, главное - чтобы функции были выполнены качественно и в срок [5]. Как только сотрудники завершают основную работу, они могут использовать высвободившееся время для решения задач в рамках собственных проектов, что свидетельствует о высокой степени социальной ответственности.

Чтобы по-настоящему внедрять инновации, компаниям необходимо обеспечивать фрормирование системы ценностей, норм, правил, предположений и убеждений сотрудников, позволяющей поддерживать эффективные способы ведения бизнеса и осуществлять практическую реализацию перспективных идей. Многие инновационные организации отслеживают все идеи персонала с помощью социальных сетей, опросов, фрестивалей, а затем отбирают лучшие из них, включая в топ-10 и затем воплощая на практике.

Компания Vodafone Group Plc реализует инициативу личного состава в формате «1 000 мелочей», в рамках которой сотрудников просят сделать одно небольшое улучшение в своей повседневной работе - не просто внести вклад в коллективное хранилище идей, но фрактически внедрить изменения в бизнес-процессы организации. Такой связующий инструмент от инновационного мышления к практическому исполнению позволяет стимулировать развитие культуры инновационной деятельности, постоянно совершенствуя взаимоотношения сотрудников через расширение прав и возможностей.

Стимулирование инновационной активности в денежном выражении или с помощью иного вида вознаграждения за усилия является лучшим методом увеличения мотивации усердно трудиться и стремиться к успеху. Руководство многих компаний часто думает, что поощрение персонала предполагает выплаты больших премий, но награда за качественно выполненную работу может выражаться в разнообразных формах и размерах. Сотрудники могут быть вознаграждены гибким графриком рабочего времени, возможностью развивать собственные идеи или возглавлять инновационный проект. 
Например, Центр инноваций аналитики консалтинговой компании Accenture, который открылся в Дублине в 2011 г., стал результатом мозгового кадрового штурма. Сотрудники, которые сгенерировали идею создания центра, приступили к ее практической реализации и претворили ее в реальность. Они составили бизнес-план и начали работать над проектом. Эффрективная деятельность персонала Accenture по учреждению Центра инноваций аналитики привела к формированию более 100 новых рабочих мест в Ирландии [6].

Руководству компаний важно создать благоприятную атмосферу с применением соответствующих методов и инструментов, представленных на рисунке 1. Такие меры поощряют инновации, позволяют организовать открытый диалог, стимулируют творчество и креативность, вдохновляют сотрудников делиться знаниями, опытом, навыками, предложениями и рекомендациями.

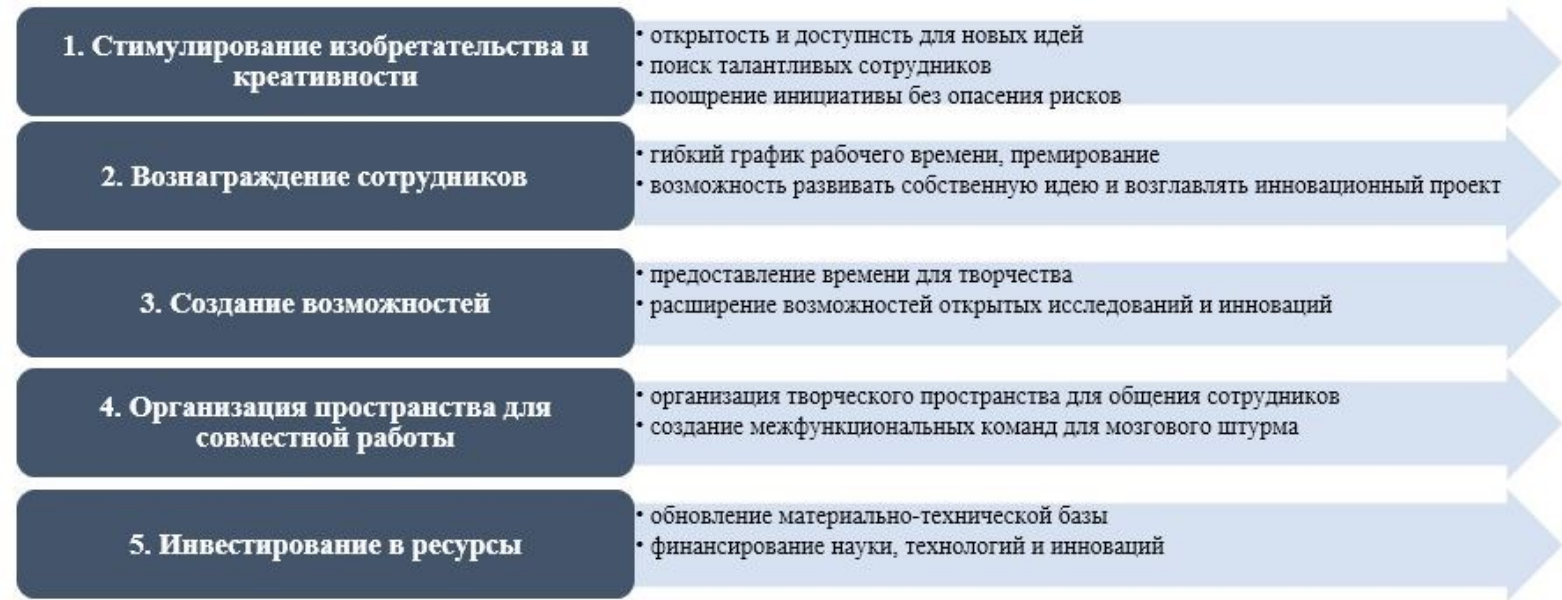

Рисунок 1 - Методы и инструменты развития культуры инновационной деятельности [7]

Компания, стремящаяся к формированию и развитию культуры инновационной деятельности, должна быть открыта для всех новых идей и творческих нестандартных решений со стороны персонала. Важно, чтобы менеджер задавал правильный тон и поощрял нововведения. Если руководство отвергает идеи, скептически относится к предложениям коллектива, сотрудники могут перестать предлагать решения существующих проблем.

Менеджмент должен положительно отзываться на все стремления персонала привнести чтото новое, даже если идея на первый взгляд не кажется перспективной. Если сотрудники убеждены, что могут потерять работу в случае неуспешной реализации проекта, они никогда не пойдут на необходимый риск для разработки революционного решения. Не каждая идея будет успешной, и компании должны быть готовы к этому. Кадровый состав не должен беспокоиться о том, что скажут руководители в случае неудачной реализации идеи [8, р. 526]. Работникам не следует бояться оспаривать статус-кво - в атмосфере страха сложно возникнуть инновационным идеям.

Культура инновационной деятельности формируется благодаря развитию коллективного чувства цели, раскрытию творческих способностей сотрудников организации и обучению их тому, как распознавать нестандартные возможности [9, с. 42]. Революционные решения, инновационные продукты или концепции долгосрочного развития позволяют компаниям опережать конкурентов [10, с. 186], в то же время быстро меняющиеся экзо- и эндогенные фракторы среды могут нивелировать полученное преимущество, сделав его недолговечным.

В связи с этим особое значение приобретает перманентный поток инновационной активности, ежедневно поддерживаемый сотрудниками компании и обеспечивающий ее устойчивое развитие, в котором она постоянно нуждается [11, р. 4136]. Инновационная среда и четкое понимание миссии организации предоставляют коллективу, осуществляющему деятельность на научно-исследовательской передовой, возможность интенсивно работать над новыми идеями, которые способствуют достижению цели предприятия.

Руководство большинства инновационных компаний ценят нестандартное мышление, заверяя участников мозгового штурма, что нет плохих идей, и убеждая их мыслить нестандартно [12, p. 73]. Лидеры создают психологическую среду, которая содействует устойчивой инновационной активности на всех уровнях организации бизнес-процессов.

По мере расширения компании управленческие и бюрократические структуры, предназначенные для определения и корректировки направлений развития, имеют тенденцию создавать препятствия для каких-либо улучшений и (или) изменений. В крупных организациях сотрудники, 
как правило, чувствуют себя оторванными от инновационной деятельности и с меньшей долей вероятности предпринимают самостоятельные действия либо предлагают революционные решения.

Приверженность формированию благоприятных психологических условий для активизации инновационной деятельности должна исходить от руководства компании. Это означает, что лидеры должны учитывать большую роль новых идей в создании и совершенствовании культуры инновационной деятельности в организации.

Таким образом, компании должны быть открыты для новшеств, поощрять творчество и изобретательность сотрудников, задавая правильный тон и стимулируя инновации. Лидерам следует объективно оценивать значимость улучшающих, а также революционных нововведений, понимать психологию новаторов и брать на себя инициативу в развитии культуры инновационной деятельности. В противном случае совершенствование в данной области невозможно. Указанный процесс зависит от множества экзо- и эндогенных фракторов, оказывающих влияние на инновационную политику предприятия. Опыт многих успешных фрирм свидетельствует, что существуют разные подходы, методы и инструменты, позволяющие создавать необходимые условия, способствующие развитию культуры инновационной деятельности. Благоприятная среда, обеспечивающая формирование собственных позиции и особенностей поведения персонала, в которых воплощаются ключевые ценности, позволяет коллективу выдвигать перспективные идеи и делать прорывные открытия независимо от отрасли или размера организации.

\section{Ссылки и примечания:}

1. Белл Д. Грядущее постиндустриальное общество : пер. с англ. М., 2004. 786 с. ; Бердяев Н.А. Смысл творчества. М., 2006. 412 с. ; Дубина И.Н. Творчество как феномен социальных коммуникаций. Новосибирск, 2000. 190 с. ; Кристенсен К. Дилемма инноватора : пер. с англ. М., 2004. 238 с. ; Майклз Э., Хэндфилд-Джонс Х., Экселрод Э. Война за таланты ; пер. с англ. 3-е изд. М., 2009. 265 с. ; Сорокин П.А. Социальная и культурная динамика. СПб., 2000. 1055 с.

2. About ByrneWallace [Электронный ресурc] // ByrneWallace : официальный сайт. URL: https://byrnewallace.com/aboutus/about-byrnewallace.html (дата обращения: 30.05.2019).

3. Intel [Электронный ресурc] : офрициальный сайт. URL: https://www.intel.ru/content/www/ru/ru/homepage.html (дата обращения: 30.05.2019).

4. Vodafone Group PIc [Электронный ресурс] : официальный сайт. URL: https://www.vodafone.com/content/index/about.html (дата обращения: 30.05.2019).

5. Ц Ценности компании [Электронный ресурс] // Atlassian : официальный сайт. URL: https://ru.atlassian.com/company/values (дата обращения: 30.05.2019).

6. Что такое Accenture? [Электронный ресурc] // Accenture : официальный сайт. URL: https://www.accenture.com/ruru/company (дата обращения: 30.05.2019).

7. Подготовлено автором.

8. Sustainable Corporate Entrepreneurship: Performance and Strategies Toward Innovation / A.K. Bräuer-Provasnek, E. Schmid, B. Geissler, G. Steiner // Business Strategy and the Environment. 2016. Vol. 26, iss. 4. P. 521-535. https://doi.org/10.1002/bse.1934.

9. Барсук М.А., Лютина А.А. Персонал как важнейший ресурс организации // Juvenis scientia. 2016. № 5. C. 41-43.

10. Алешина И.В. Глобализация и маркетинг инновационной культуры // Вестник университета. 2016. № 1. С. 184-188.

11. Griesar K., Bessant J., Bernschneider-Reif S. The Recipe for Corporate Longevity: From the Perspective of "Managing Innovation" // Angewandte Chemie International Edition. 2018. Vol. 57, iss. 16. P. 4130-4142.

12. Richter N., Jackson P., Schildhauer T. Outsourcing Creativity: An Abductive Study of Open Innovation Using Corporate Accelerators // Creativity and Innovation Management. 2017. Vol. 27, iss. 1. P. 69-78. https://doi.org/10.1111/caim.12252.

\section{References:}

Alyoshina, IV 2016, 'Globalization and Marketing of Innovative Culture', Vestnik universiteta, no. 1, pp. 184-188, (in Russian). Barsuk, MA \& Lyutina, AA 2016, 'Staff as a Primary Resource of an Organization', Juvenis scientia, no. 5, pp. 41-43, (in Russian). Bräuer-Provasnek, AK, Schmid, E, Geissler, B \& Steiner, G 2016, 'Sustainable Corporate Entrepreneurship: Performance and Strategies Toward Innovation', Business Strategy and the Environment, vol. 26, iss. 4, pp. 521-535, https://doi.org/10.1002/bse.1934.

Bell, D 2004, The Coming of Post-Industrial Society, Moscow, 786 p., (in Russian).

Berdyaev, NA 2006, The Meaning of Creativity, Moscow, 412 p., (in Russian).

Christensen, CM 2004, The Innovator's Dilemma: When New Technologies Cause Great Firms to Fail, Moscow, 238 p., (in Russian).

Dubina, IN 2000, Creativity as a Phenomenon of Social Communications, Novosibirsk, 190 p., (in Russian).

Griesar, K, Bessant, J \& Bernschneider-Reif, S 2018, 'The Recipe for Corporate Longevity: From the Perspective of "Managing Innovation"', Angewandte Chemie International Edition, vol. 57, iss. 16, pp. 4130-4142, https://doi.org/10.1002/anie.201712514.

Michaels, E, Handfield-Jones, H \& Axelrod, B 2009, The War for Talent, $3^{\text {rd }}$ ed., Moscow, 265 p., (in Russian).

Richter, N, Jackson, P \& Schildhauer, T 2017, 'Outsourcing Creativity: An Abductive Study of Open Innovation Using Corporate Accelerators', Creativity and Innovation Management, vol. 27, iss. 1, pp. 69-78, https://doi.org/10.1111/caim.12252.

Sorokin, PA 2000, Social and Cultural Dynamics, Saint Petersburgh, 1055 p., (in Russian). 